Check for updates

Cite this: RSC Adv., 2017, 7, 26440

Received 24th February 2017

Accepted 3rd May 2017

DOI: $10.1039 / c 7 r a 02319 g$

rsc.li/rsc-advances

\section{Temperature-induced reversible micelle-vesicle transition in aqueous solution of a pseudogemini surfactant without any additive $\uparrow$}

\author{
Xuemin Liu, (D)* Jingwen Wang, Zhenggang Cui, ${ }^{*}$ Heping Yao, Xin Ge, Wen Chen \\ and Fengli Sun
}

\begin{abstract}
Temperature-induced reversible micelle-vesicle transition is achieved in aqueous solution of a single pseudogemini surfactant without any additive. The pseudogemini surfactant is constructed by tetradecyldimethylamine (DA14) and maleic acid (MA) at a 2:1 molar ratio of DA14/MA in aqueous solution via non-covalent bonds. The transition temperature can be adjusted by changing either the total surfactant concentration or the DA14/MA ratio. This reversible system, which has both low material costs and convenience, has potential applications in household and industry fields.
\end{abstract}

\section{Introduction}

Micelles and vesicles are different types of self-assemblies; ${ }^{\mathbf{1 2}}$ the mutual transition between them exhibits importance in various fields such as demulsification in oil recovery, ${ }^{3}$ material separation, ${ }^{4,5}$ and drug delivery and release. ${ }^{6-9}$ Usually this transition is induced by changing external conditions, including light, ${ }^{\mathbf{1 0}}$ $\mathrm{pH},{ }^{11} \mathrm{CO}_{2},{ }^{12-14}$ temperature, ${ }^{15-17}$ or introducing additives like hydrophobic amphiphiles ${ }^{\mathbf{1 8 , 1 9}}$ and inorganic salts ${ }^{\mathbf{2 0 , 2 1}}$ etc. Amongst these measures, most attention has been devoted to temperature due to its convenience in controlling and reversing, which makes the transition easily cycled or suspended on demand.

The temperature-induced transition is commonly achieved using mixing surfactant systems, for example, cationic/anionic, zwitterionic/anionic, and cationic/cationic mixed systems. Huang et $a .^{15,17}$ first reported a temperature-induced micelleto-vesicle transition (MVT) in a cationic (dodecyltriethylammonium bromide)/anionic (sodium dodecyl sulfate) surfactant system, and it was observed that the transition from cylindrical micelles to vesicles was accompanied by an increase in turbidity of the solution with increasing temperature. Wang et $a{ }^{22}$ reported effects of temperature on the transition of aggregates in a mixed system of ammonium gemini surfactant $\mathrm{C}_{12} \mathrm{C}_{4}(\mathrm{OH})_{2} \mathrm{C}_{12} \mathrm{Br}_{2}$ with anionic amino acid monomeric surfactant $\mathrm{C}_{12} \mathrm{Glu}$. A series of transition of surfactant aggregates was observed upon increasing the temperature, e.g. from small

Key Laboratory of Synthetic and Biological Colloids, Ministry of Education, School of Chemical and Material Engineering, Jiangnan University, Wuxi 214122, P. R. China. E-mail: lxm@jiangnan.edu.cn; cuizhenggang@hotmail.com

$\dagger$ Electronic supplementary information (ESI) available: The ${ }^{1} \mathrm{HNMR}$, negative staining TEM, and surface tension results obtained for 14-MA-14 aqueous solutions. See DOI: 10.1039/c7ra02319g spherical micelles to large vesicles, from vesicles to solid spherical aggregates and further to larger irregular aggregates, as well as from entangled wormlike micelles to branched wormlike micelles. These temperature-triggered transitions of surfactant aggregates can be elucidated on the basis of temperatureinduced variations in dehydration, electrostatic interaction, hydrogen bond of the headgroups and hydrophobic interactions between the hydrocarbon chains. This suggests that surfactants with multiple binding sites may possess improved regulation ability and temperature sensitivity. It is predicted that the temperature-induced MVT is in general easily achieved for cationic/anionic mixed surfactant systems due to relatively stronger molecular interactions and larger micelle aggregation numbers. In addition, temperature-induced MVT has also been observed for other mixed surfactant systems. For example, Li et al. ${ }^{23}$ described a temperature-induced MVT in cationic/cationic mixed surfactant systems, dodecyltrimethylammonium chloride/ didodecyldimethylammonium bromide. By means of the geometric rule, they explained that the transformation of the organized assemblies with temperature is a result of the variation of average headgroup area. They also reported temperature and $\mathrm{pH}$ dual responsive self-assembly transitions, or transitions from vesicle to micelle (VMT) and from micelle to vesicle, in aqueous solutions of a zwitterionic (dodecyl sulfobetaine)/anionic (sodium bis(2-ethylhexyl) sulfosuccinate) mixed system. ${ }^{24}$

It is already known that gemini surfactants, which possess double hydrocarbon chains and double headgroups connected by a spacer group, could display richer aggregation behavior than conventional surfactants. ${ }^{25,26}$ With the advantage of avoiding complicated synthetic and purification procedures compared with the conventional gemini surfactants through covalent bonds, another kind of gemini surfactants formed by non-covalent bonds (pseudogemini surfactants) have been widely reported by the groups of R. K. Thomas, ${ }^{27}$ Y. Feng, ${ }^{28,29}$ 
and Y. Wang. ${ }^{\mathbf{3 0 , 3 1}}$ This strategy has been proposed in several very comprehensive reviews by X. Zhang ${ }^{32}$ and Y. Wang. ${ }^{33}$ In constructing the pseudogemini surfactant by non-covalent bonds, as reported in the aforementioned literature, the building blocks focus mainly on interacting with single-chain surfactants or gemini surfactants and bola-type connecting molecules containing double or multiple binding sites, without cumbersome organic synthesis and complicated purification. However, in most cases the pseudogemini surfactants contain excess small counterions, introduced by the cationic and/or anionic surfactants, and excess inorganic salt. Therefore, it is necessary to find a method for preparing salt-free pseudogemini surfactants and reveal their solution behavior. Dong et al. ${ }^{34}$ observed a micelle to vesicle transition in an aqueous solution of $N, N^{\prime}$ dialkyl- $N, N^{\prime}$-di(ethyl-2-pyrrolidone)ethylenediamine, and the transition was influenced by $\mathrm{pH}$ and concentration. Zheng et $a .^{35,36}$ have designed a pseudogemini surfactant by combining anionic surfactant, sodium dodecyl benzene sulfonate (SDBS or DS), with small cationic spacers, [mim- $\mathrm{C}_{4}-\mathrm{mim}$ ] $\mathrm{Br}_{2}$ and [mpy- $\left.\mathrm{C}_{4}-\mathrm{mpy}\right] \mathrm{Br}_{2}$, and observed rich lamellar structures, such as unilamellar and multilamellar vesicles, planar bilayers, and lamellar liquid crystals. Nevertheless, to the best of our knowledge, no work has been reported for such a structural transition induced by temperature in single surfactant systems without the use of an additive.

In this study, we report temperature-triggered MVT and VMT observed in the aqueous solution of a salt-free pseudogemini surfactant, tetradecyldimethylamine (DA14), in combination with maleic acid (MA) via non-covalent bonding, named as 14MA-14. The chemical structure of 14-MA-14 is shown in Scheme 1, which has been confirmed by ${ }^{1}$ HNMR spectra (Fig. S1, ESI $\dagger$ ).

The reversible MVT and VMT phenomena, which are unusual for an individual surfactant solution, have been confirmed by various experimental techniques such as turbidity, dynamic light scattering (DLS), as well as cryotransmission electron microscopy (cryo-TEM).

\section{Experimental}

\subsection{Materials and instrumentation}

Tetradecyldimethylamine (DA14, $\geq 99 \%$ ) was prepared from tetradecanol and $\mathrm{N}, \mathrm{N}$-dimethylamine in the presence of a $\mathrm{Cu}-\mathrm{Ni}$ solid catalyst and distilled. Maleic acid (MA, 99.5\%, Sipo Chemical Co. Ltd, China) was used without further purification. All solutions were prepared with ultrapure water $(18.2 \mathrm{M} \Omega \mathrm{cm})$.

${ }^{1} \mathrm{HNMR}$ spectra were recorded on a Bruker AV400 NMR spectrometer at $400 \mathrm{MHz}$ using $\mathrm{CDCl}_{3}$ as the solvent,

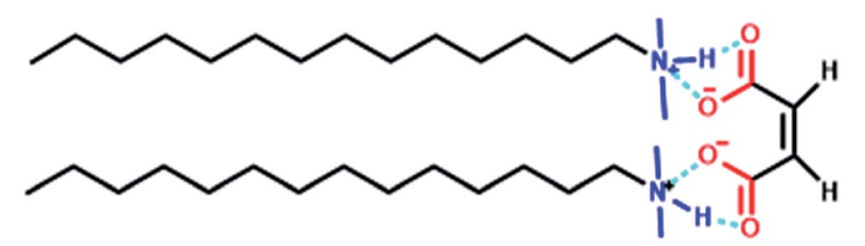

Scheme 1 Chemical structure of the pseudogemini surfactant 14MA-14.
Switzerland Bruker Company. The critical aggregation concentration (CAC) of the surfactant solutions were recorded using the optical contact angle tensiometer (OCA 40 micro, Data physics, Germany), Beijing Dong Fang Defei Instrument Company. Absorbance was recorded using UV-vis spectrophotometer (UV-2700) equipped with a Peltier electronic temperature-controlling device, Shimadzu Instrument Company. DLS measurements were performed on a ALV/DLS/ SLS-5022F (HOSIC LIMITED, Germany). Cryo-TEM microscopy analysis was also carried out (JEOL Model JEM-2100). Conductivity was obtained using a Toledo conductivity meter (FE30), Mettler Toledo Shanghai Instrument Company.

\subsection{General procedure for the pseudogemini surfactant preparation}

The surfactant 14-MA-14 results from a stoichiometric proton transfer from the acid (MA) to the amine (DA14) in aqueous media. The addition of DA14 to MA in an aqueous solution under stirring was conducted at $25{ }^{\circ} \mathrm{C}$ with molar ratio of $2: 1$, until a homogeneous solution was obtained. All prepared solutions were stored for $24 \mathrm{~h}$ prior to the measurement. The solid surfactant was obtained by evaporating it from its aqueous solution with ethanol and then drying in a vacuum.

\subsection{Characterization of pseudogemini surfactant (14-MA-14)}

The structure of 14-MA-14 was confirmed by characterization using ${ }^{1} \mathrm{HNMR}$ (Fig. S1, ESI $\dagger$ ), white solid, ${ }^{1} \mathrm{HNMR}(400 \mathrm{MHz}$, $\left.\mathrm{CDCl}_{3}, \mathrm{TMS}\right): \sigma(\mathrm{ppm}) 0.89\left(\mathrm{t}, 6 \mathrm{H}, 2\left(\mathrm{CH}_{3}-\mathrm{CH}_{2}-\right)\right), 1.26(\mathrm{~m}, 44 \mathrm{H}$, $\left.2\left(\mathrm{CH}_{3}\left(\mathrm{CH}_{2}\right)_{11}-\mathrm{CH}_{2}-\right)\right), 1.62\left(\mathrm{~m}, 4 \mathrm{H}, 2\left(\mathrm{CH}_{3}-\left(\mathrm{CH}_{2}\right)_{11}-\mathrm{CH}_{2}-\mathrm{CH}_{2}-\mathrm{N}-\right)\right)$, $2.56\left(\mathrm{~s}, 12 \mathrm{H}, 2\left(\mathrm{~N}\left(\mathrm{CH}_{3}\right)_{2}\right)\right), 2.67\left(\mathrm{t}, 4 \mathrm{H}, 2\left(\mathrm{CH}_{3}-\left(\mathrm{CH}_{2}\right)_{11}-\mathrm{CH}_{2}-\right.\right.$ $\left.\mathrm{CH}_{2}-\mathrm{N}\right)$ ), 6.29 (m, 2H, OOC-CH=CH-COO-).

\subsection{UV-vis absorbance}

The turbidity of the aqueous solution of 14-MA-14 at different temperatures was estimated by measuring the absorbance of the solution at $600 \mathrm{~nm}$ using a UV-vis spectrophotometer (UV2700), equipped with a Peltier electronic temperaturecontrolling device.

\subsection{Dynamic light scattering (DLS)}

Dynamic light scattering (DLS) was used to study the aggregate size and size distribution of the 14-MA-14 aqueous solution. A Nano ZS Zetasizer ALV/DLS/SLS-5022F (HOSIC LIMITED, Germany) was employed to measure the size of the aggregates at $90^{\circ}$ scattering angle with a He-Ne laser $(\lambda=632.8 \mathrm{~nm})$. The 14-MA14 aqueous solutions prepared were filtered through a hydrophilic PVDF membrane filter $(0.22 \mu \mathrm{m})$ to remove possible dust particles before measurement. To obtain the apparent hydrodynamic radius $\left(R_{\mathrm{h}}\right)$, the intensity autocorrelation functions were analyzed using CONTIN. The results presented are averages of triplicate measurements.

\subsection{Cryogenic transmission electron microscopy (TEM)}

Cryogenic Transmission Electron Microscopy (Cryo-TEM) observation was carried out with a transmission electron 
microscopy (JEOL Model JEM-2100). For obtaining the cryoTEM images, two 14-MA-14 (DA14/MA = $2: 1$ ) aqueous solution samples were prepared in a controlled environment verification system (CEVS) at $25{ }^{\circ} \mathrm{C}$ and $33{ }^{\circ} \mathrm{C}$, respectively. Then, 4 $\mu \mathrm{L}$ sample solution was coated onto a TEM copper grid, and two pieces of filter papers were employed to blot the grid for about 4 seconds to form a thin film. The grid was then quickly plunged into a reservoir of liquid nitrogen $\left(-165^{\circ} \mathrm{C}\right)$ and kept in liquid nitrogen until being observed. After transferring the grid to a cryogenic sample holder (Gatan 626) and putting the holder into a JEOL JEM-1400 Plus TEM $(120 \mathrm{kV})$ instrument at about $-174^{\circ} \mathrm{C}$, the nanostructures were imaged.

\subsection{Conductivity-temperature relation}

Conductometry experiments were carried out with a (MettlerToledo, FE30) conductometer using a cell of cell constant $=$ $0.01 \mathrm{~cm}^{-1}$. All measurements were taken in a double-walled glass container at $25-40{ }^{\circ} \mathrm{C}$ maintained by a DC-2006 circulating bath with an accuracy of $\pm 0.1^{\circ} \mathrm{C}$. After being stirred for 2 minutes and balanced for 5 minutes, the conductivity was recorded. Reproducibility of results was checked from three repeat experiments.

\subsection{Phase behaviour}

Partial ternary phase diagrams were examined by preparing a series of surfactant solutions at different concentrations in the molar ratio of DA14/MA from 1.2 to 2, and then these solutions in $100 \mathrm{~mL}$ volumetric flasks were left into a low-constant temperature bath (DC-2006) to equilibrate for 2 days. The temperature was thermostated to within $0.2{ }^{\circ} \mathrm{C}$ at 25,35 , and $45{ }^{\circ} \mathrm{C}$, respectively. The phase behaviour was confirmed by the UV-vis method.

\section{Results and discussion}

\section{1 $T_{M V T}$ and micelle-vesicle transition characterization}

The turbidity of the aqueous solution of 14-MA-14 (DA14/MA = $2: 1$ ) at different temperatures was estimated by measuring the absorbance of the solution at $600 \mathrm{~nm}$ using a UV-vis spectrophotometer (UV-2700) equipped with a Peltier electronic temperature-controlling device. The concentration of 14-MA-14 $(\mathrm{DA} 14 / \mathrm{MA}=2: 1)$ in the solution is fixed at $0.7 \mathrm{mM}$, a little higher than the critical aggregation concentration (CAC) of the pseudogemini surfactant $\left(0.56 \mathrm{mM}, 25{ }^{\circ} \mathrm{C}\right.$, Fig. S2, ESI $\left.\dagger\right)$. The results are shown in Fig. 1 . It is seen that the absorbance of the solution stays very low $(<0.01$, colorless clear solution) below $32{ }^{\circ} \mathrm{C}$, but increases almost linearly with increasing temperature beyond $32{ }^{\circ} \mathrm{C}(>0.01$, turbid and slightly bluish solution). After this point, the absorbance increases continually with increasing temperature, reaching about 0.1 at $42{ }^{\circ} \mathrm{C}$, which however, decreases to original value on cooling the solution, and the values are almost reversible at temperature between $20{ }^{\circ} \mathrm{C}$ and $42{ }^{\circ} \mathrm{C}$. The break point in the absorbance curve thus gives a temperature $\left(32{ }^{\circ} \mathrm{C}\right)$ indicating that the state of aggregation has been changed into another state in the solution, which is consistent with the direct visual observation of the change in
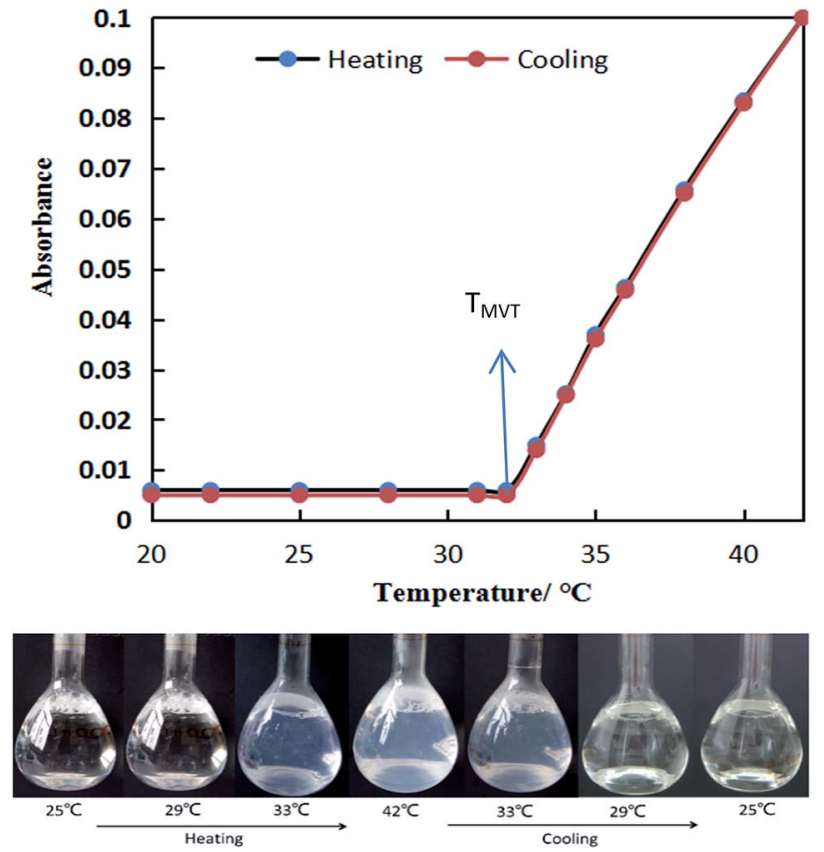

Fig. 1 Absorbance at $600 \mathrm{~nm}$ and photographs of 14-MA-14 (DA14/ $M A=2: 1,0.7 \mathrm{mM}$ ) aqueous solution as a function of temperature.

turbidity. In this study, this temperature is defined as the temperature of self-assembly transition from micelle to vesicle $\left(T_{\mathrm{MVT}}\right)$ or from vesicle to micelle $\left(T_{\mathrm{VMT}}\right)$, and the $T_{\mathrm{MVT}}$ or $T_{\mathrm{VMT}}$ of 14-MA-14 solution is confirmed by the UV-vis spectroscopy method.

To confirm the morphology of the aggregates in the 14-MA14 system, two 14-MA-14 (DA14/MA = 2:1, $0.7 \mathrm{mM}$ ) aqueous solution samples were prepared at $25{ }^{\circ} \mathrm{C}\left(<T_{\mathrm{MVT}}\right.$ or $\left.T_{\mathrm{VMT}}\right)$ and $33{ }^{\circ} \mathrm{C}\left(>T_{\mathrm{MVT}}\right.$ or $\left.T_{\mathrm{VMT}}\right)$, and cryo-TEM and negative staining TEM images were obtained, which are shown in Fig. 2 and S3 (ESI $\dagger$ ), respectively. Clearly, the aggregates shown in Fig. $2 \mathrm{a}\left(25^{\circ} \mathrm{C}\right)$ are mostly spherical micelles with diameters of about $10 \mathrm{~nm}$, whereas in Fig. $2 \mathrm{~b}$ and $\mathrm{S} 3 \dagger$ (both $33{ }^{\circ} \mathrm{C}$ ) vesicles with diameters of about $100 \mathrm{~nm}$ can be distinctly identified. It can then be concluded that in the 14-MA-14 (DA14/MA = $2: 1$ ) increasing temperature of the aqueous solution triggers a micelle-to-
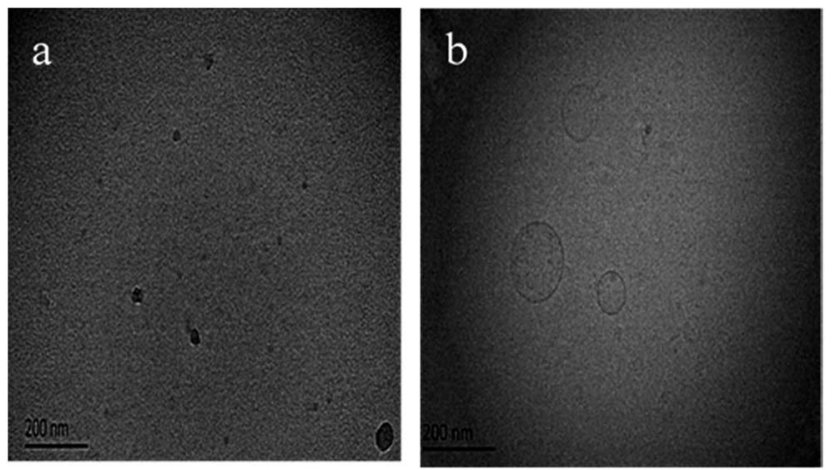

Fig. 2 Cryo-TEM images of 14-MA-14 (DA14/MA = 2:1) aqueous solutions of $0.7 \mathrm{mM}$ at $25^{\circ} \mathrm{C}$ (a) and $33^{\circ} \mathrm{C}$ (b). 
vesicle transition (MVT), which is a reversible process, or a vesicle-to-micelle transition (VMT) can be triggered by decreasing temperature.

To further explore the variation of the aggregate structure, the size and size distribution of the aggregates in 14-MA-14 (DA14/MA = 2:1) aqueous solution of $0.7 \mathrm{mM}$ were measured by dynamic light scattering (DLS). The results are averages of triplicate measurements, which are shown in Fig. 3. It is seen that below $T_{\mathrm{MVT}}\left(26-29^{\circ} \mathrm{C}\right)$, with increasing temperature of the 14-MA-14 solution, the average $R_{\mathrm{h}}$ of the aggregates increases from $\sim 10 \mathrm{~nm}$ to $\sim 100 \mathrm{~nm}$, suggesting a transition of aggregate structure from spherical micelles to vesicles. However, beyond $T_{\mathrm{MVT}}\left(33-42{ }^{\circ} \mathrm{C}\right)$, the $R_{\mathrm{h}}$ remains unchanged $(100 \mathrm{~nm})$ but with a narrower distribution, revealing that vesicles are the main aggregates, and the self-assembly is in the form of vesicles not micelles, which is consistent with the results in UV-vis absorbance or direct visual observation of the change in turbidity (Fig. 1).

\subsection{Micelle-vesicle transition temperature}

Further study indicates that the MVT temperature of the 14-MA14 aqueous solution is not constant but depends on both the DA14/MA molar ratio and the pseudogemini surfactant concentration.

Fig. 4 indicates that the MVT temperature of the 14-MA-14 system is strongly dependent on the DA14/MA molar ratio in the aqueous solution. The system with $1.0 \mathrm{mM}$ of the pseudogemini surfactant (DA14/MA $=2: 1$ ) gives a MVT temperature of $38{ }^{\circ} \mathrm{C}$; however, on decreasing the DA14/MA molar ratio (decreasing concentration of DA14 and with non-changing concentration of MA Table S1 (ESI) $\dagger$ ), the MVT temperature increases, reaching $43{ }^{\circ} \mathrm{C}$ at a DA14/MA molar ratio of $1.2: 1$, and the MVT phenomenon disappears when DA14/MA molar ratio approaches $1: 1$. Herein no pseudogemini surfactants are formed theoretically, which is favored to form vesicles. In other

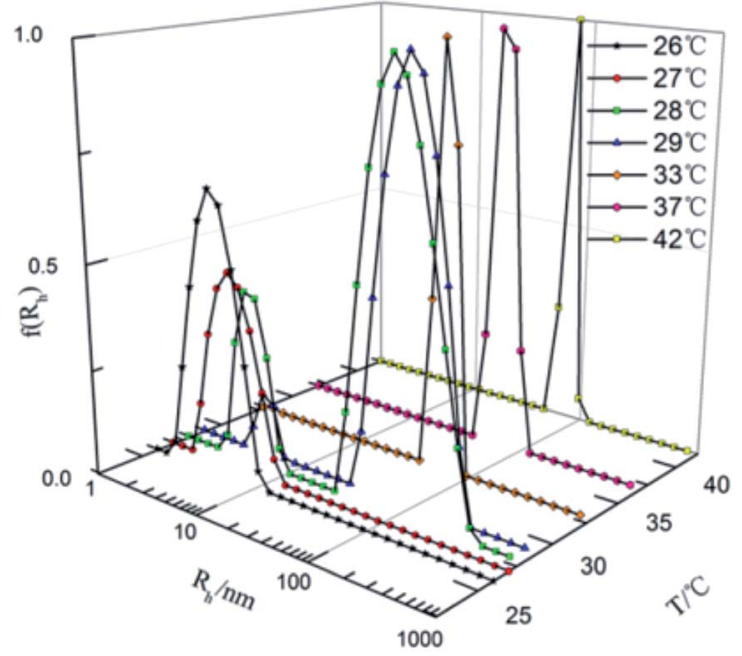

Fig. 3 Hydrodynamic radii $\left(R_{\mathrm{h}}\right)$ of aggregates and its distribution in 14MA-14 (DA14/MA = $2: 1$ ) aqueous solution of $0.7 \mathrm{mM}$ as a function of temperature.

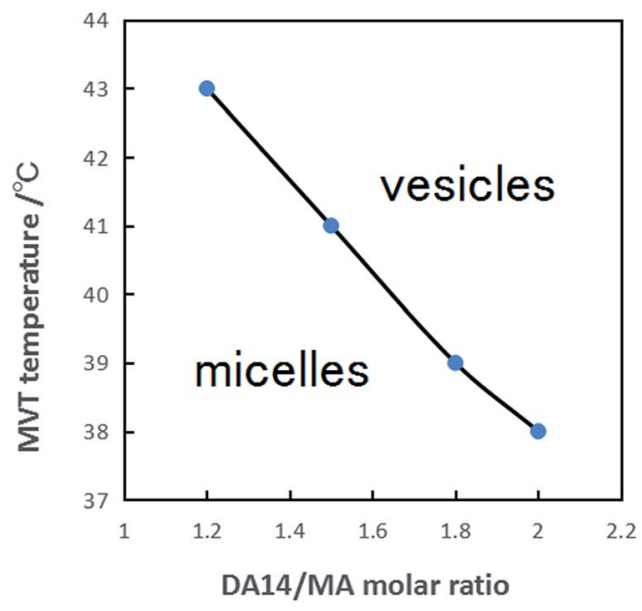

Fig. 4 MVT temperature of the 14-MA-14 (1.0 mM) aqueous solutions as a function of DA14/MA molar ratio.

words, only pseudogemini surfactants are formed, and micelles to vesicles transition can be easily achieved in this system. Similar results in prolonged sonication double-chained cationic surfactant (didodecyldimethylammonium bromide) were also observed by Evans. ${ }^{37,38}$

Fig. 5 shows that at fixed DA14/MA molar ratio (2:1), the MVT temperature decreases significantly with decreasing concentration of the pseudogemini surfactant in the solution. For example, the MVT temperature decreases from $38{ }^{\circ} \mathrm{C}$ at $1.0 \mathrm{mM}$ to $32{ }^{\circ} \mathrm{C}$ at $0.7 \mathrm{mM}$ (Table S1 (ESI) $\dagger$ ), this means that the micelles-vesicles transition is induced by dilution at the temperature range from $32{ }^{\circ} \mathrm{C}$ to $38{ }^{\circ} \mathrm{C}$. A similar phenomenon has been reported in the mixed surfactant systems containing bile salts or block copolymers or hydrotropic mixtures, and a bola-type supra-amphiphiles. ${ }^{39-44}$

As is already shown in Fig. 4 and 5, the MVT temperature can be affected by either the total surfactant concentration or the DA14/MA molar ratio, and clearly these two factors interact with each other. To verify whether the DA14-MA-water system forms vesicles or not, a partial determination of the ternary phase

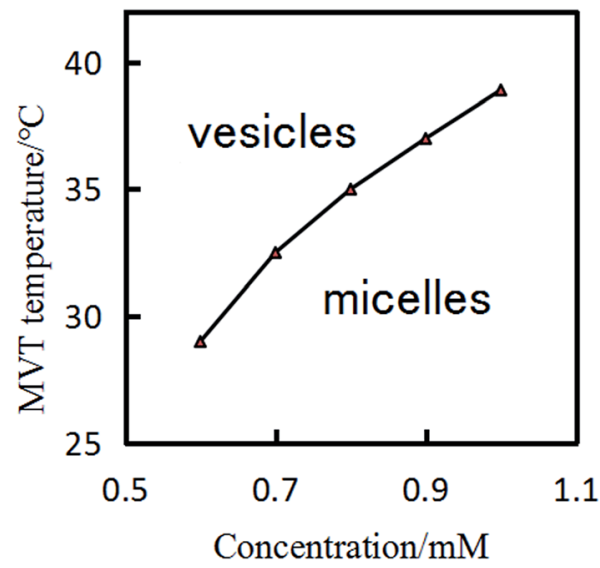

Fig. 5 MVT temperature of the 14-MA-14 (DA14/MA = 2:1) aqueous solutions as a function of pseudogemini surfactant concentration. 
diagram at different temperatures, particularly the water-rich region of the isotropic solution region $\left(W_{\text {water }}>99 \%\right.$, concentration is $0.5-2 \mathrm{mM}$ ), was made by changing the total surfactant concentration and the DA14/MA molar ratio. In Fig. 6, the phase diagram can be thought of as consisting of two parts: one is the pseudogemini surfactant (14-MA-14, 2 : 1 molar ratio of DA14/ MA)-water-excess DA14 (right of phase diagram in Fig. 6), which is a two-phase region and not transparent; the other is the surfactant (a cationic surfactant with an organic counterion after the proton transfer from MA to DA14 at a chemometrically molar ratio of DA14/MA, left of phase diagram in Fig. 6)-waterexcess MA, which consists of only one one-phase region including one-phase of surfactant monomer aqueous solution ( $<$ CAC, no micelles and vesicles formation), one-phase micelles or one-phase vesicles. From Fig. 6, the temperature-induced reversible micelle-vesicle transition phenomenon appears at DA14/MA molar ratio region from $2: 1$ to $1: 1$, and vesicles region enlarges with increasing temperature, i.e. vesicles region at $45{ }^{\circ} \mathrm{C}$ (more than $T_{\mathrm{MVT}}$ ) is significantly larger than that at $35{ }^{\circ} \mathrm{C}$ (a little more than $T_{\mathrm{MVT}}$ ), while there is no vesicles region at $25{ }^{\circ} \mathrm{C}$ (less than $\left.T_{\mathrm{MVT}}\right)$. At a constant DA14/MA molar ratio, the temperature-induced reversible micelle-vesicle transition phenomenon appears with decreasing concentration of the pseudogemini surfactant in solution (>CAC); this means that the micelles-vesicles transition could also be induced by dilution if the temperature is higher than $T_{\mathrm{MVT}}$.

\subsection{Mechanism for MVT induced by temperature}

According to the above results, how temperature drives the morphological transitions of the aggregates in 14-MA-14 aqueous solutions can be understood by two respects. First, 14-MA-14 surfactant is combined by the strong attraction between oppositely charged surfactant headgroups, and therefore, it also has nonionic character to the micelles. Heating causes dehydration of headgroups and leads to the decrease in the equilibrium area per molecule at the aggregates surface, which promotes the formation of vesicles. Second, the "pseudogemini" structure of 14-MA-14, the $2: 1$ stoichiometric complex between DA14 and MA, is not as stable as that of a real spacer in the gemini surfactant since the electrostatic attractions are a weaker physical force as compared to a chemical bond. Thus, 14-MA-14 can dissociate to meet the different

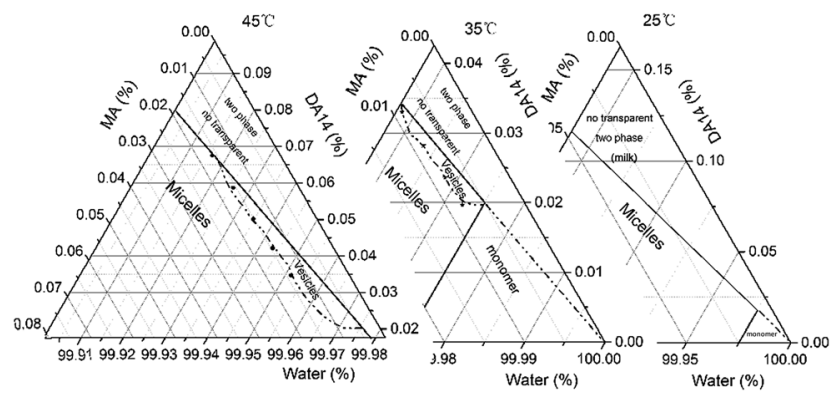

Fig. 6 Part of phase diagram at $25,35,45^{\circ} \mathrm{C}$ for the system DA14MA-water.

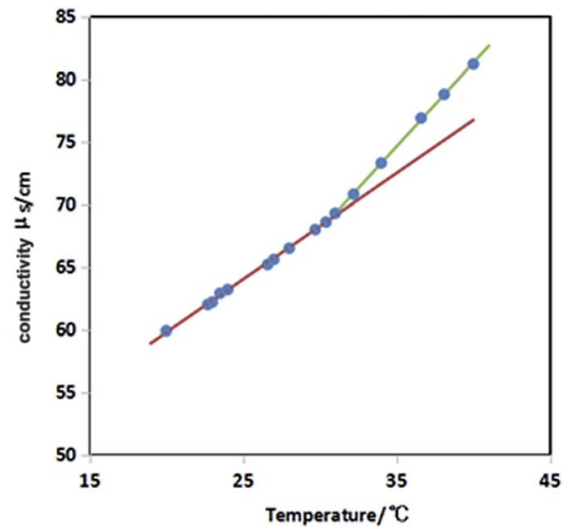

Fig. 7 Conductivity in 14-MA-14 (DA14/MA $=2: 1$ ) aqueous solution of $0.7 \mathrm{mM}$ as function of temperature.

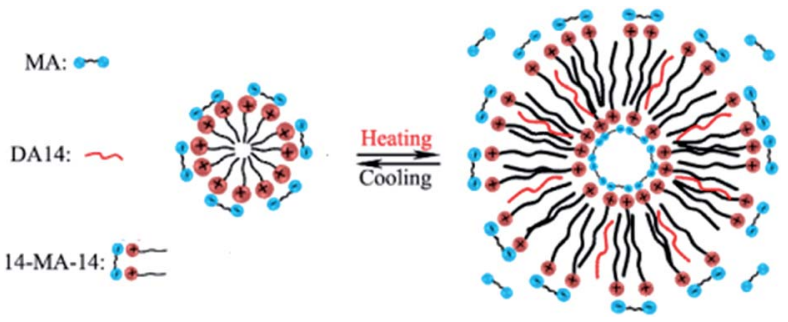

Scheme 2 Schematic of the micelles-vesicles transition induced by temperature in the 14-MA-14 aqueous solutions.

curvatures of the self-assembly and there should be other species coexisting in the solution (Fig. S4 (ESI) $\dagger$ ). Upon heating, the weak noncovalent electrostatic attractions will probably decrease substantially, and a fraction of "pseudogemini" surfactant will be destroyed. ${ }^{45,46}$ The desorbed DA14 from destroyed "pseudogemini" surfactant will join to form the new mixed micelles because of solubilization of DA14, and these micelles will grow and transform into vesicles (Fig. S5 (ESI) $†$ ); whilst the desorbed MA may tend into bulk aqueous solution, the conductivity of the 14-MA-14 aqueous solution $0.7 \mathrm{mM}$, $\mathrm{DA} 14 / \mathrm{MA}=2: 1$ ) will increase significantly with increase in the temperature. The break point in Fig. 7 gives an MVT temperature $\left(32{ }^{\circ} \mathrm{C}\right)$, and the $\mathrm{pH}$ of the 14-MA-14 aqueous solution also decreases from 6.38 at $25{ }^{\circ} \mathrm{C}$ to 6.02 at $40{ }^{\circ} \mathrm{C}$ (Fig. S6 (ESI) $\dagger$ ).

Therefore, such desorption, if it occurs, would increase the tail volume and reduce the effective headgroup area according to the concept of 'critical packing' parameter proposed by Israelachvili, ${ }^{\mathbf{4}}$ thereby driving the micelles to aggregates of lower curvatures specifically to vesicles. The schematic of the temperature-induced micelles-vesicles transition in 14-MA-14 aqueous solutions is shown in Scheme 2.

\section{Conclusion}

In this study, the pseudogemini surfactant is constructed by tetradecyldimethylamine (DA14) and maleic acid (MA) at a $2: 1$ molar ratio of DA14/MA in aqueous solution via non-covalent 
bonds, and temperature-induced reversible micelle-vesicle transition is achieved in aqueous solution of this single pseudogemini surfactant without any additive. The transition temperature can be adjusted by changing either the total surfactant concentration or the DA14/MA ratio in the range of $32{ }^{\circ} \mathrm{C}$ to $43{ }^{\circ} \mathrm{C}$. This reversible system is a combination of low cost materials and convenience, and has potential applications in drug delivery and release systems.

\section{References}

1 H. Hoffman, Adv. Mater., 1994, 6, 116.

2 P. Walde, H. Umakoshi, P. Stano and F. Mavelli, Chem. Commun., 2014, 50, 10177.

3 S. B. Gogoi, Indian J. Chem. Technol., 2010, 17, 282.

4 B. Haddou, J. P. Canselier and C. Gourdon, Sep. Purif. Technol., 2006, 50, 114.

5 W. L. Hinze and E. Pramauro, Crit. Rev. Anal. Chem., 1993, 24, 133.

6 M. B. Yatvin, J. N. Weinstein and W. H. Dennis, Science, 1978, 202, 1290.

7 Q. W. Zha, Q. L. Xie, Y. M. Hu, J. Han, L. L. Ge and R. Guo, Colloid Polym. Sci., 2016, 294, 841.

8 W. Li and T. Luo, Langmuir, 2015, 31, 5141.

9 W. X. Gu, Q. L. Li, H. G. Lu, L. Fang, Q. X. Chen, Y. W. Yang and H. Gao, Chem. Commun., 2015, 51, 4715.

10 J. Eastoe and A. Vesperinas, Soft Matter, 2005, 1, 338.

11 H. Kawasaki, M. Souda and S. Tanaka, J. Phys. Chem. B, 2002, 106, 1524.

12 Z. B. Zheng, C. Y. Liu and W. H. Qiao, Eur. J. Lipid Sci. Technol., 2015, 117, 1673.

13 W. Li, J. L. Zhang, S. Q. Cheng, B. X. Han, C. X. Zhang, X. Y. Feng and Y. J. Zhao, Langmuir, 2008, 25, 196.

14 W. Li, Y. J. Yang, T. Luo, J. L. Zhang and B. X. Han, Phys. Chem. Chem. Phys., 2014, 16, 3640.

15 H. Q. Yin, Z. K. Zhou, J. B. Huang, R. Zheng and Y. Q. Zhang, Angew. Chem., 2003, 115, 2238.

16 Y. M. Li, H. X. Zhang, Z. N. Wang and M. T. Bao, Colloid Polym. Sci., 2014, 292, 2349.

17 H. Q. Yin, J. B. Huang, Y. Y. Lin, Y. Q. Zhang, S. C. Qiu and J. Q. Ye, J. Phys. Chem. B, 2005, 109, 4104.

18 X. R. Zhang, J. B. Huang, M. Ma, S. H. Tang and B. Y. Zhu, Colloid Polym. Sci., 2001, 279, 1245.

19 L. Li, Y. Yang, J. Dong and X. F. Li, J. Colloid Interface Sci., 2010, 343, 504.

20 N. Vlachy, M. Drechslerb, J. M. Verbavatz, D. Tourauda and W. Kunza, J. Colloid Interface Sci., 2008, 319, 542.

21 A. Mohanty, T. Patra and J. Dey, J. Phys. Chem. B, 2007, 111, 7155 .
22 X. L. Ji, M. Z. Tian and Y. L. Wang, Langmuir, 2016, 32, 972. 23 Y. J. Yang, L. F. Liu, X. Huang, X. N. Tan, T. Luo and W. Li, Soft Matter, 2015, 11, 8848.

24 W. Li, Y. J. Yang, L. F. Liu, X. N. Tan, T. Luoa and J. Y. Shen, Soft Matter, 2015, 11, 4283.

25 R. Zana, J. Colloid Interface Sci., 2002, 248, 203.

26 F. M. Menger and C. A. Littau, J. Am. Chem. Soc., 1991, 113, 1451.

27 J. Penfold, R. K. Thomas and P. Li, J. Colloid Interface Sci., 2015, 449, 167.

28 Y. Zhang and Y. Feng, J. Colloid Interface Sci., 2015, 447, 173.

29 Y. Zhang, Y. Feng, Y. Wang and X. Li, Langmuir, 2013, 29, 4187.

30 D. Yu, M. Tian, Y. Fan, G. Ji and Y. Wang, J. Phys. Chem. B, 2012, 116, 6425.

31 Y. Tang, Z. Liu, L. Zhu, Y. Han and Y. Wang, Langmuir, 2015, 31, 2104.

32 X. Zhang and C. Wang, Chem. Soc. Rev., 2011, 40, 94.

33 L. Zhu, Y. Tang and Y. Wang, J. Surfactants Deterg., 2016, 19, 237.

34 Z. Jiang, J. Liu, K. Sun, J. F. Dong, X. F. Li, S. Z. Mao, Y. R. Du and M. L. Liu, Colloid Polym. Sci., 2014, 292, 739.

35 N. Sun, L. J. Shi, F. Lu, S. T. Xie and L. Q. Zheng, Soft Matter, 2014, 10, 5463.

36 L. J. Shi, F. Y. Chen, N. Sun and L. Q. Zheng, Soft Matter, 2015, 11, 4075.

37 B. W. Ninham, D. F. Evans and G. J. Wei, J. Phys. Chem., 1983, 87, 5020 .

38 J. E. Brady, D. F. Evans, B. Kachar and B. W. Ninham, J. Am. Chem. Soc., 1984, 106, 4279.

39 H. Shen and A. Eisenberg, J. Phys. Chem. B, 1999, 103, 9473.

40 Z. Hu, A. M. Jonas, S. K. Varshney and J. F. Gohy, J. Am. Chem. Soc., 2005, 127, 6526.

41 S. U. Egelhaaf and P. Schurtenberger, Phys. Rev. Lett., 1999, 82, 2804.

42 M. A. Long, E. W. Kaler and S. P. Lee, Biophys. J., 1994, 67, 1733.

43 B. F. B. Silva, E. F. Marques and U. Olsson, Langmuir, 2008, 24, 10746.

44 D. Xia, L. Shangguan, M. Xue and B. Shi, New J. Chem., 2016, 40, 9890.

45 Y. J. Feng and Z. L. Chu, Soft Matter, 2015, 11, 4614.

46 T. S. Davies, A. M. Ketner and S. R. Raghavan, J. Am. Chem. Soc., 2006, 128, 6669.

47 J. N. Israelachvili, D. J. Mitchell and B. W. Ninham, J. Chem. Soc., Faraday Trans. 1, 1976, 72, 1525. 